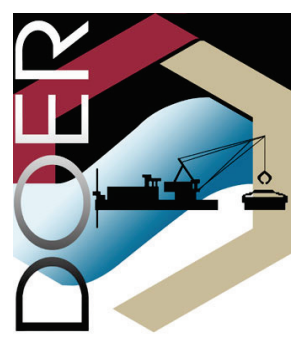

ERDC TN-DOER-E41

March 2017

\title{
A Method for Simulating Sedimentation of Fish Eggs to Generate Biological Effects Data for Assessing Dredging Impacts
}

by Justin L. Wilkens and Burton C. Suedel

PURPOSE: The purpose of this technical note is to describe a methodology for generating and evaluating the effects of sedimentation caused by dredging on aquatic species, including the effects of burial on emergence of fish larvae from eggs. This methodology has wide applicability for evaluating sedimentation originating from dredging activities, as well as other causes of sedimentation (e.g., agricultural practices, storm events, tidal flows).

BACKGROUND AND PROBLEM: Many naturally spawning fish populations experience high levels of mortality during the egg stage. This may be due to angling, nest predation, poor spawning substrate, severe storm or wind and wave action dislodging eggs, and fungus (e.g., Johnson 1961; Scott and O'Bier 1962; Dahlberg 1979; Steinhart et al. 2005). Additionally, excessive natural and anthropogenic sedimentation may increase egg mortality by burying the eggs (Ventling-Schwank and Livingstone 1994; Berry et al. 2011).

Most egg burial research has focused on salmonids. This research has shown that different grain sizes of sediment can affect egg survival differently and sedimentation of finer-grained sediment particles $(<0.85 \mathrm{~mm})$ can be the most detrimental to fish eggs (Reiser and White 1988; Greig et al. 2005; Jensen et al. 2009; Bowerman et al. 2014). The organic matter in the sediment can decompose and use dissolved oxygen. The interstitial water associated with burial may also affect the rate of transfer of dissolved substances into, or from the sediment which can effect egg respiration leading to development deficiencies and mortality (Silver et al. 1963). Additionally, larvae that do hatch may be unable to emerge and hence become entombed.

Dredging is an activity that may result in sedimentation. As a result, many Federal dredging projects are restricted to environmental windows $(\mathrm{EW})$. Regulators impose EWs to restrict dredging and placement activities to certain periods of the year minimizing the potentially adverse impacts associated with these activities (Reine et al. 1998; Suedel et al. 2008). However, evaluating the impact of dredging on the burial of fish eggs is problematic because so few data exist for many of the species for which EWs are designed to protect.

EXPOSURE CHAMBER: There are many variations and options that can be used to construct an exposure chamber addressing the effects of sedimentation. Commercially available products such as glass beakers may meet experimental needs, although these usually have a slightly convex bottom that may confound the creation of a consistent sediment layer. Regardless of the exposure chamber type, every chamber must be able to hold fish eggs, introduce and remove sediment, flow test water through the chamber without disturbing the sediment layer, and contain screens to prevent fish from escaping. The ability to accurately measure sediment depth and 
water quality in the chamber is a critical consideration. Figure 1 illustrates critical components in chamber construction, while Figure 2 shows a completed exposure chamber constructed of a transparent material which allows observation of the instrument used to measure sediment depth. The chamber described in this paper has been used successfully in both freshwater (carbon filtered tap water Vicksburg, MS) and saltwater (30 ppt; Instant Ocean, United Pet Group; Cincinnati, $\mathrm{OH}$ ) using sediments of varying grain size.

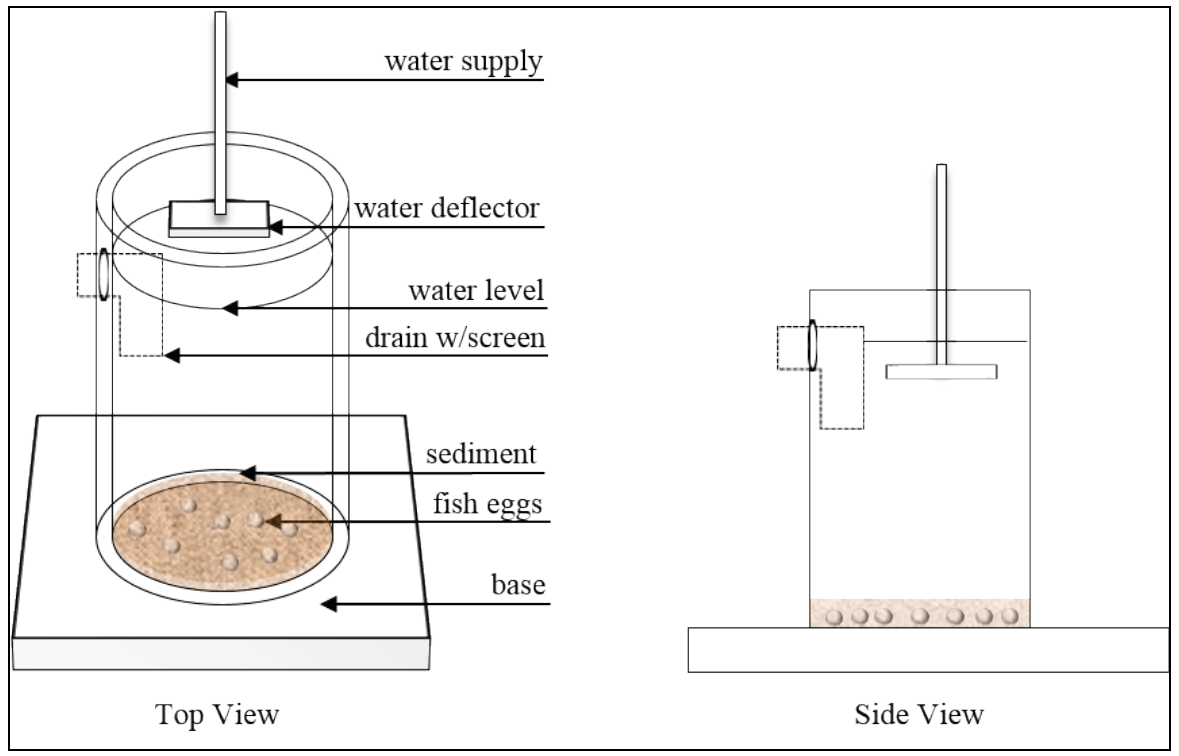

Figure 1. Exposure chamber illustrating major components.

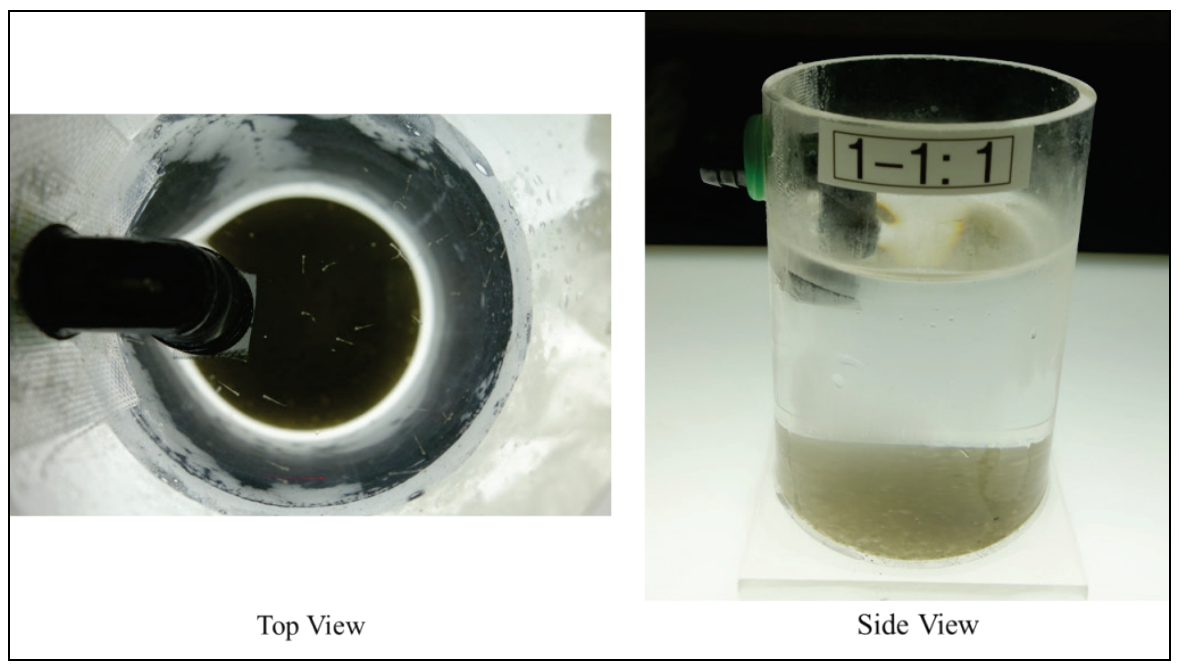

Figure 2. Exposure chamber completed (without water deflector).

To meet project objectives the exposure chamber was $6.35 \mathrm{~cm}$ diameter (internal diameter) by $10.16 \mathrm{~cm}$ long and was made of clear acrylic pipe (Figure 2). The pipe was attached to a $7.62 \mathrm{~cm}^{2}$ base of clear acrylic sheet. A drain $(1.27 \mathrm{~cm}$ diameter) was drilled $1.27 \mathrm{~cm}$ from the top of the chamber to maintain a volume of approximately $260 \mathrm{ml}$. Rubber bands (Castration Bands, Neogen Corporation; Lansing, MI) were used to install an elbow tube fitting $(1.27 \mathrm{~cm}$ hose by $1.27 \mathrm{~cm}$ 
hose, inside diameter, black high-density polyethylene [HDPE] elbow, United States Plastic Corporation; Lima, $\mathrm{OH}$ ) in the overflow drain with the elbow extending into the chamber. A rubber band coated with silicone was installed between the chamber and the first elbow barb on both the inside and outside the chamber. This created a water-tight seal and prevented test organisms from escaping around the elbow. Silicone was used to attach a $150 \mu \mathrm{m}$ screen (Nylon screen, Pentair Aquatic Eco-Systems; Sanford, NC) onto the end of the elbow located inside the chamber to prevent escape. This design allowed for the screened portion of the elbow to be completely submerged in the water thereby preventing organisms from being entrained on the screen. Air bubbles may also be introduced near the screen to help prevent larvae from clogging the screen. The water stream entering the chamber is deflected by a $2.54 \mathrm{~cm}^{2}$ acrylic sheet that was submerged just beneath the water surface; thereby preventing disturbance of the sediment layer.

SEDIMENT: Test sediments to date have been collected from shoaled areas in navigational channels. Such sediments are routinely dredged in close proximity to species of concern, and are of known contamination. For the experiments, sediments were analyzed for chemical contamination, grain size distribution and other physical and chemical characteristics that assist in evaluating effects to test organisms. Sediments collected within the expected dredge prism were typically collected using a grab sampler, placed in plastic buckets, and shipped to the Engineer Research and Development Center (ERDC). In the laboratory, the samples were composited, mechanically homogenized, and then sub-sampled and submitted for chemical and physicochemical analyses. In preparation for the experiment, the remaining sediments were mixed and sieved (through $1 \mathrm{~cm}$ ) to remove large debris. Depending on the dredge operation and site-specific conditions, the sediment may be sieved through smaller mesh screens to yield particle sizes such as fine sands, silts, and clays that would most likely migrate away from the dredge and settle on organisms and life stages of concern.

CREATING A SEDIMENT LAYER: There are several ways to create a sediment layer in an exposure chamber, each depending on well-defined correlations between sediment weight (wet or dry) and sediment depth in the exposure chamber. Once initial measurements have been taken, a simple linear regression can be used to model the relationship and make predictions on sediment depth based on sediment weight values to more quickly achieve desired depths. The sediment layer described herein was created by testing regression predictions using several sediments collected from marine coastal environments.

First, each sediment sample was weighed (wet, to the nearest $0.0001 \mathrm{~g}$ ) in a small plastic weighing dish and then rinsed into a container where it was mechanically mixed to create slurry. Next, the slurry contents were rinsed with test water into the exposure chamber. The chamber was then submerged approximately halfway into a water bath for temperature control, and the sediment was allowed to settle for 24 hours prior to the first measurement. The sediment depth was measured (to the nearest $0.01 \mathrm{~mm}$ ) using a stainless steel digital caliper (VWR Digital Calipers, catalog number 62379-531, VWR; Radnor, PA). To prevent the buildup of sediment between the depth plunger and the chamber while lowering it through the sediment layer a fine metal point was attached to the calipers' plunger (Figure 6).

To prepare for the measurement, the exposure chamber was removed from the water bath and placed on a stable, flat surface. The caliper, clamped on a stand and positioned over the chamber, 
was lowered until it was submerged approximately halfway into the chamber or approximately 2$3 \mathrm{~cm}$ above the sediment surface. Next, the caliper fine adjustment knob was used to slowly lower the caliper depth plunger until it touched the sediment surface. The caliper was then zeroed. To aide in viewing the sediment surface, a digital, single-lens reflex camera (DSLR; Nikon D90) equipped with a large macro lens (AF micro Nikkor 200 mm 1:4 D, Nikon Inc.; Melville, NY) was used to view the sediment surface through the transparent chamber. The camera image was projected onto a high definition monitor (720p) via a mini-HDMI cord. A magnifier light mounting bracket may also be used to view the chamber. An external light source was placed near the exposure chamber to cast a shadow on the depth plunger to help detect when it touched the sediment surface.

Last, the fine adjustment knob was used to slowly lower the plunger through the sediment until it touched the bottom of the chamber. The resulting caliper reading represented sediment depth and was recorded. A total of eight measurements were taken within each chamber to determine sediment layer variability. Figure 3 illustrates the layout of the points measured to determine sediment depth. The resulting measurements were used to confirm a target depth or a linear regression was used to model the new data and predict the next sediment weight to test (Figure 4).

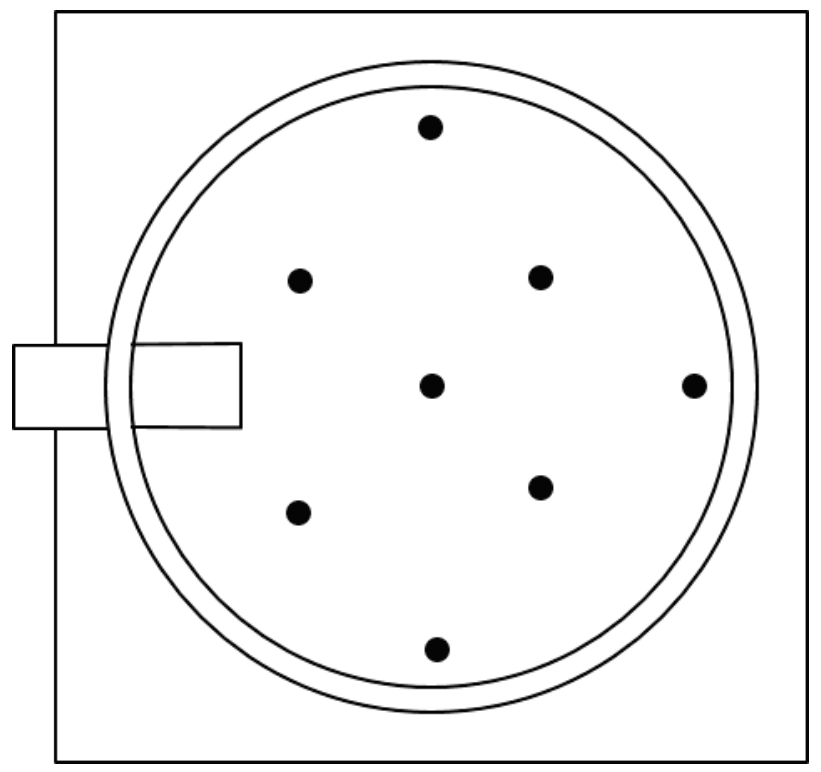

Figure 3. An illustration showing the bottom of an exposure chamber. The black dots represent the general area where a measurement was taken to measure sediment depth variability. 


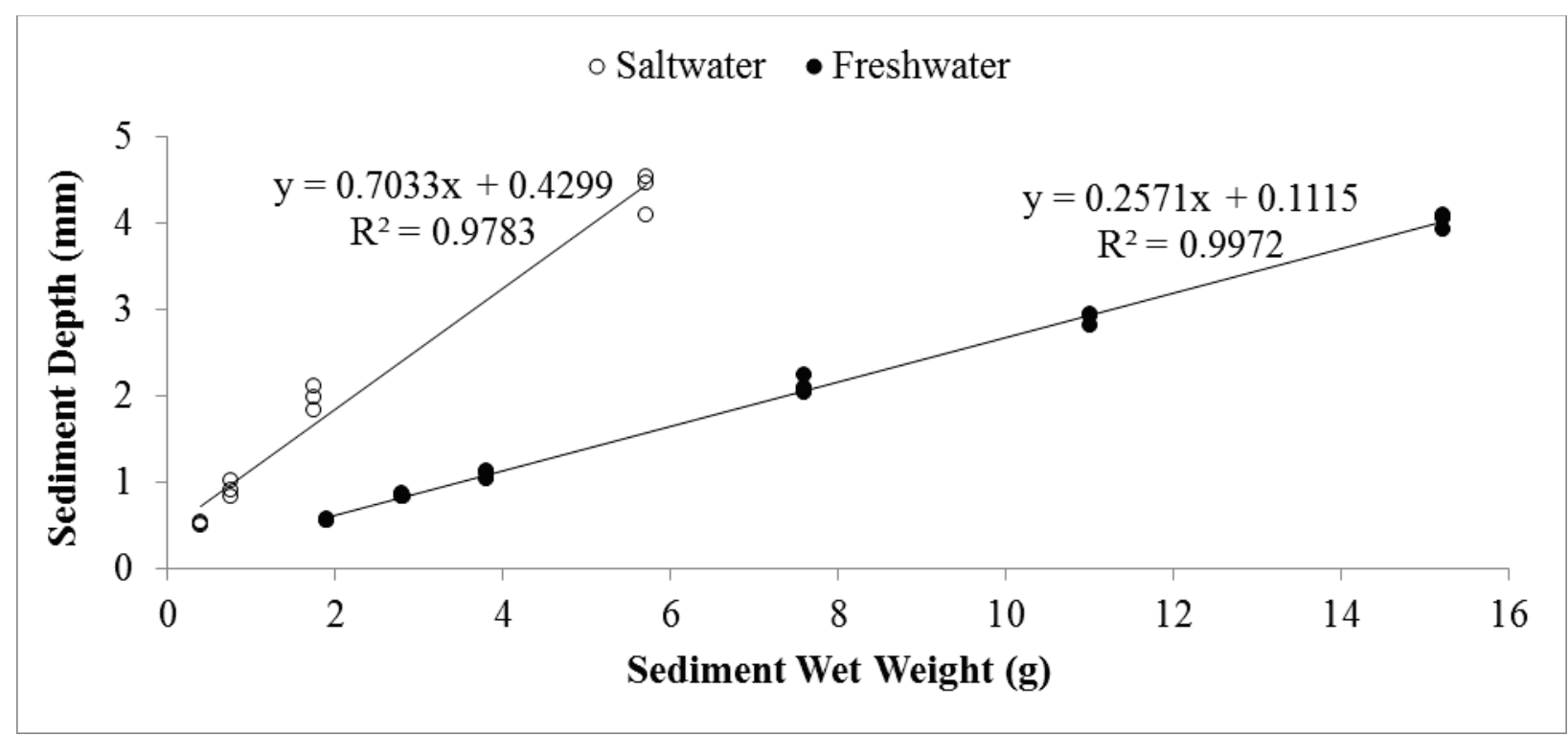

Figure 4. Simple linear regression modeling sediment depth against sediment wet weight.

QUANTIFYING SEDIMENTATION PERFORMANCE: Sediments may settle out individually, but more commonly they form flocs or aggregates composed of many particles adhering to each other resulting in settling rates much quicker than if settling individually. Physicochemical factors such as organic matter content, salinity, temperature, hardness and $\mathrm{pH}$ affect the rate of flocculation (Sutherland et al. 2014; Kranck 1980; Wechsler and Cogley 1977). An influential variable measured in exposure chambers was salinity of the test water. Clay and silt particles have negative charges. In freshwater, these particles repel each other; therefore, the flocculation process is weakened, and more particles settle out individually whereas in saltwater sodium and chloride neutralize the electrical charges and particles form flocs and settle quickly (Sutherland et al 2014). In exposure chambers constructed to date, sediment was allowed to settle for 24 hours. Total suspended sediment (TSS as $\mathrm{mg} / \mathrm{L}$ ) was then measured prior to the first introduction of laboratory water. In freshwater, TSS averaged $50 \mathrm{mg} / \mathrm{L}$ while in saltwater (30 ppt) TSS was $<4 \mathrm{mg} / \mathrm{L}$. Similarly, Sutherland et al. (2014) found that sedimentation of kaolin clay in freshwater took tens of hours while in saltwater with salinity greater than $10 \mathrm{ppt}$ the particles settled in tens of minutes.

Comparable amounts of sediment resulted in a sediment layer approximately twice as deep in exposure chambers where saltwater was introduced in comparison to freshwater. This is most likely a result of the sediments lower density and formation of larger flocs in saltwater (Ani et al. 1991) (Figure 4). Sediment settling out of the water column in the exposure chambers formed a bed layer that initially was deeper in both freshwater and saltwater. Over time, this layer slowly consolidated in the chamber (Figure 5). 


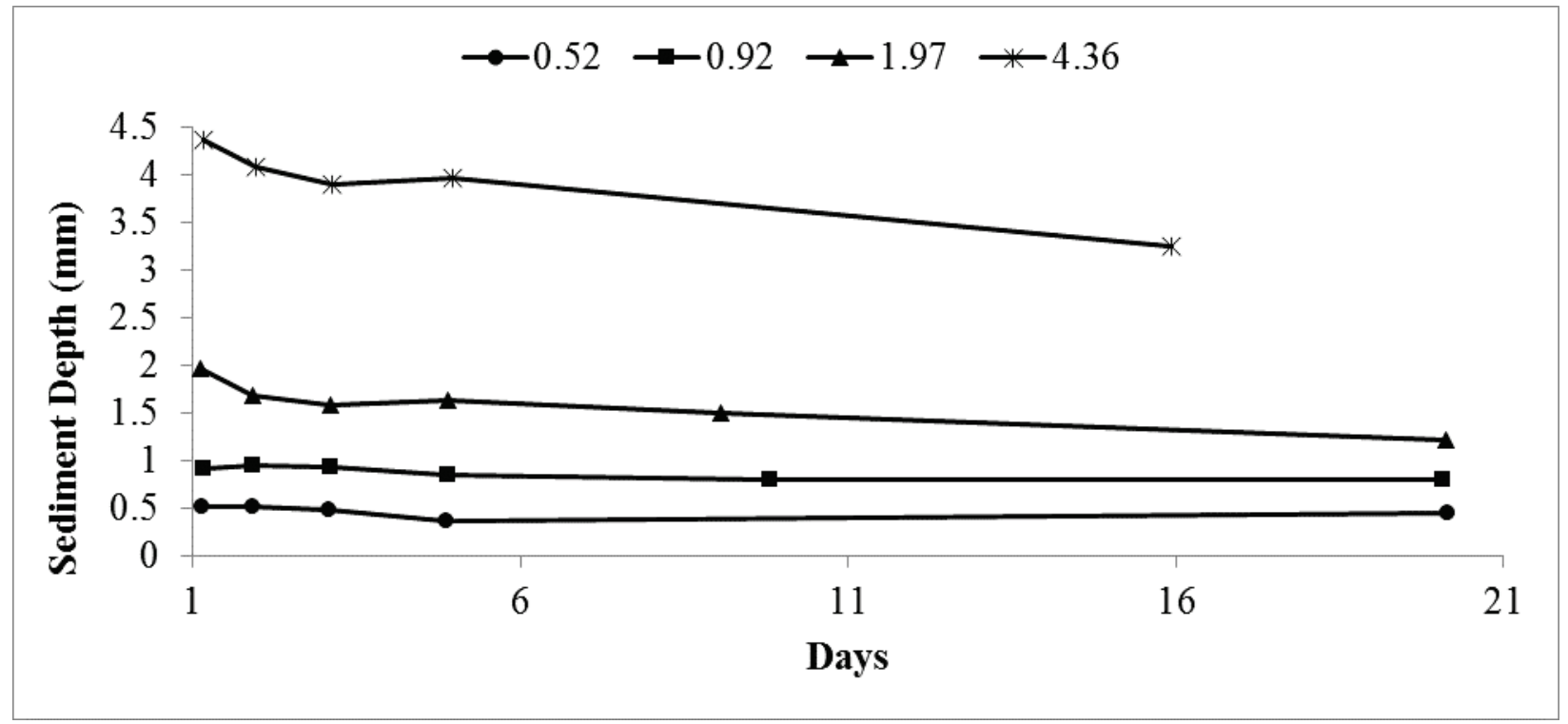

Figure 5. Change in exposure chamber sediment depth using artificial saltwater (30 ppt).

A quiescent environment was necessary after the slurry was added to an exposure chamber to reduce uneven settling of sediment at the bottom of the chamber. Depth measurements taken near the center of the chamber were compared with those near the perimeter. In saltwater, the change in depth from the side of the chamber to the middle increased by an average slightly greater than $50 \%$ for the layer calculated to be $2 \mathrm{~mm}$, but as target depth increased to approximately 4-5 $\mathrm{mm}$, this decreased to less than $20 \%$. The variability in sediment depth is apparent when looking through the bottom of the chamber at lower sediment depths (Figure 6). Further testing revealed vibration was the main variable affecting how the sediment settled at the bottom of the chamber. When chambers were submerged half way into a water bath, the sediment accumulated more in the middle of the chamber. Although the chambers did not float, their density was likely decreased and probably made them more susceptible to vibration in the experimental area. To reduce vibration when the sediment was initially settling, the chambers were placed in a refrigerator (to maintain temperature) on a leveled anti-vibration platform specifically designed for laboratory bench scales for the first 24 hours. The platform effectively minimized vibration and resulted in a more even distribution of sediment. The chambers were then placed into a water bath where sediment distribution remained unaffected for the remainder of the experiment. Seismic vibrations, acoustic vibrations, and forces applied directly to the experimental area all may affect the distribution of sediment at the bottom of the chamber when sediment is settling. Improvements to minimize vibration in the experimental area should be made when practical.

EXPERIMENTAL CONSIDERATIONS: A method for delivering water to multiple exposure chambers while controlling temperature must be a consideration when planning an experiment. Sedimentation experiments were performed in the Fish Larvae and Egg Exposure System (FLEES) located at the ERDC (Lutz et al. 2012). The FLEES is a versatile exposure system equipped with a data acquisition device and LabVIEW software (National Instruments; Austin, TX). The design automates tasks such as the introduction of water, which allows for an easy retrofit to meet many experimental needs. 
For the sedimentation experiments, exposure chambers were partially submerged into temperature controlled FLEES water baths after sediment settled on the anti-vibration platform. A Zumwalt water delivery apparatus (Zumwalt et al. 1994) was used to deliver water introduced by FLEES into eight exposure chambers simultaneously. The Zumwalt apparatus is a glass, water-splitting chamber with eight holes drilled in the glass bottom. Silicone stoppers are drilled with a core borer and used to hold $50 \mathrm{ml}$ polypropylene syringes in place in the glass bottom. Water was dispensed through 16 gauge, $1.5 \mathrm{in}$. needles with the sharp points removed. Dispensing needles may also be used. For each needle, a small hole was drilled near the top of the needle cover, and then the cover was placed back over the needle. A $2.54 \mathrm{~cm}^{2}$ piece of flat acrylic sheet was cut, and then a hole large enough to friction fit the needle cover was drilled in the middle. The needle cover was pushed through the hole until it extended just beyond the surface of the opposite side. Silicone was used to glue the cover in place. The needle and cover were installed onto the syringe. The Zumwalt apparatus was attached to threaded stainless steel rods and lowered until the acrylic square was submerged just beneath the water surface in the chamber. The Zumwalt apparatus was leveled by adjusting the nylon nuts on the stainless steel rods. Water introduced into the Zumwalt apparatus exited the syringe through the needle cover and was diffused by the deflector plate. This effectively prevented the sediment layer from being disturbed. Twelve Zumwalt delivery apparatuses (four per water bath) were used simultaneously to perform the sedimentation experiments.

Monitoring activities included measuring water quality and quantity, sediment depth, and observing exposure chambers for effects. The FLEES automation is ideal for maintaining water quality. If water quality begins to deteriorate, the water flow can be increased by changing the computer program. To avoid adverse water quality, sufficient water is introduced to equal the volume of the chamber at least once per day. Generally, higher volume exchanges can be used to ensure suitable water quality conditions so long as sediment depths are not compromised. Water in each chamber may also be aerated with glass Pasteur pipettes to maintain dissolved oxygen near the temperature-dependent level of saturation.

CONCLUSION: This technical note described a methodology designed for evaluating the effects of sedimentation/burial of aquatic species at critical life stages (e.g., burial of fish eggs and emergence of larvae from eggs). FLEES is a versatile system and can be easily retrofitted to meet a variety of experimental needs related to sedimentation, including testing sedimentation effects originating from many sources (e.g., agriculture, storm event, tidal flows) on multiple aquatic species and life stages. Multiple experimental factors including sediment type and location (freshwater versus saltwater), settling time, vibration, and consolidation are important considerations for accurately measuring sediment depth in such experiments. Demonstrated accuracy and repeatability of sediment depth measurements in such studies are critical for generating sedimentation effects data deemed acceptable by the regulatory community for assessing dredging risks to aquatic life. 
$\underline{\text { Bottom }}$

$0.52 \mathrm{~mm}$

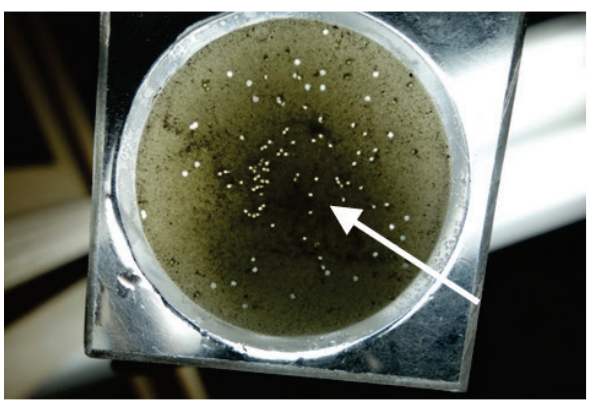

$0.92 \mathrm{~mm}$

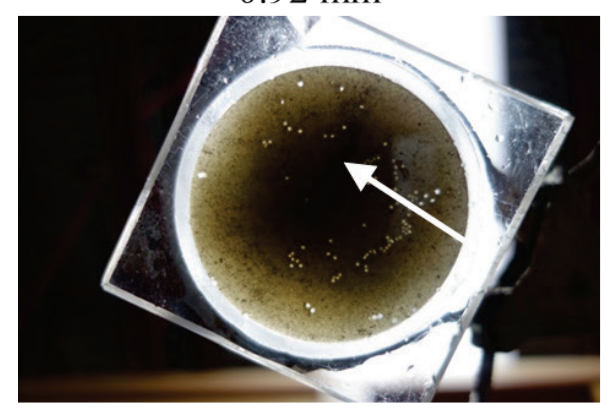

$1.97 \mathrm{~mm}$

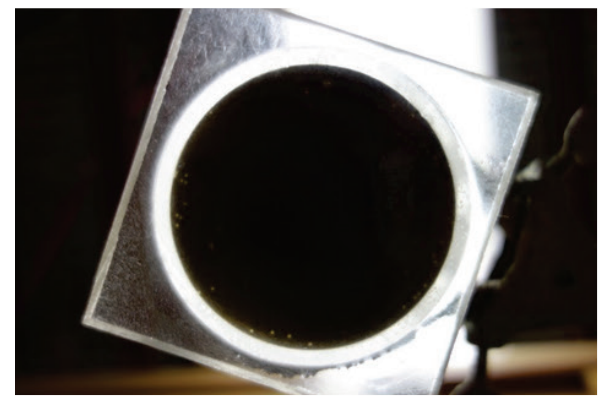

$4.36 \mathrm{~mm}$

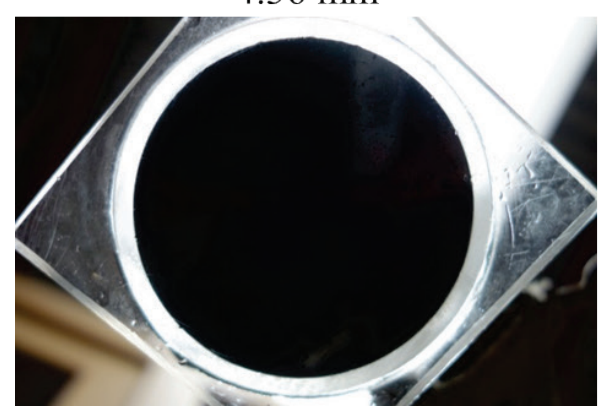

Top

$0.52 \mathrm{~mm}$

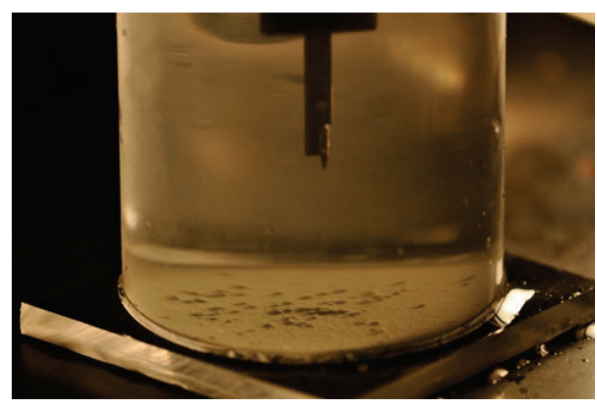

$0.92 \mathrm{~mm}$

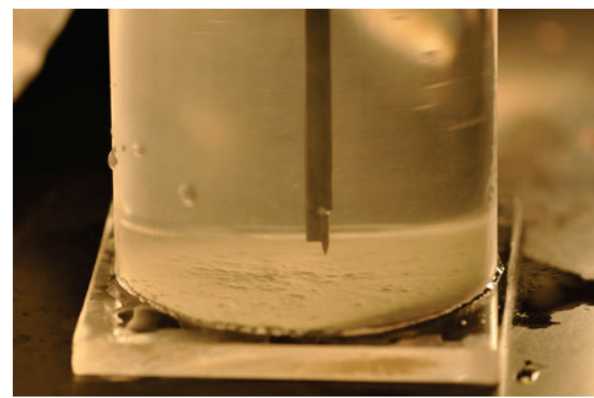

$1.97 \mathrm{~mm}$

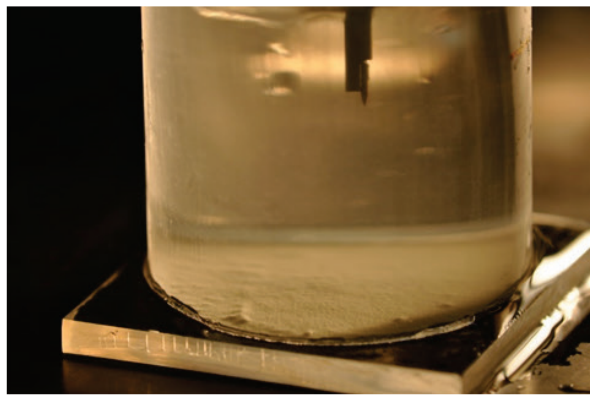

$4.36 \mathrm{~mm}$

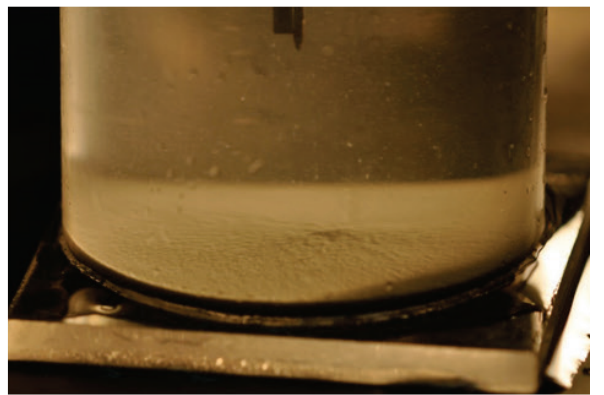

Figure 6. Demersal fish eggs $(0.75 \mathrm{~mm}$ diameter) buried under $0.52,0.92$, 1.97 , and $4.36 \mathrm{~mm}$ of sediment in artificial saltwater (30 ppt). Arrows point to an area where the sediment is more concentrated on the bottom. 
POINTS OF CONTACT: For additional information, contact Justin Wilkens (601-634-2421, Justin.L.Wilkens@usace.army.mil),or Dr. Burton Suedel (601-634-4578, Burton.Suedel@usace. army.mil ). This technical note should be cited as follows:

Wilkens, J. L., and B. C. Suedel. 2017. A method for simulating sedimentation of fish eggs to generate biological effects data for assessing dredging impacts. DOER Technical Notes Collection. ERDC TN-DOER-E41. Vicksburg, MS: U.S. Army Engineer Research and Development Center. http://el.erdc.usace.army.mill.

\section{REFERENCES}

Ani, S. A., K. R. Dyer, and D. A. Huntley. 1991. Measurement of the influence of salinity on floc density and strength. Geo-Marine Letters 11(3):154-158. DOI: 10.1007/BF02431002.

Berry, W. J., N. J. Rubinstein, E. K. Hinchey, G. Klein-MacPhee, and D. G. Clarke. 2011. Assessment of dredginginduced sedimentation effects on winter flounder (Pseudopleuronectes americanus) hatching success: results of laboratory investigations. In Proceedings of the Western Dredging Association Technical Conference and Texas A\&M Dredging Seminar, June 5-8. Nashville, Tennessee.

Bowerman, T., B. T. Neilson, and P. Budy. 2014. Effects of fine sediment, hyporheic flow, and spawning site characteristics on survival and development of bull trout embryos. Canadian Journal of Fisheries and Aquatic Sciences 71(7):1059-1071.

Dahlberg, M. D. 1979. A review of the survival rates of fish eggs and larvae in relation to impact assessment. Marine Fisheries Review 41(3):1-12.

Greig, S. M., D. A. Sear, D. Smallman, and P. A. Carling. 2005. Impact of clay particles on the cutaneous exchange of oxygen across the chorion of Atlantic salmon eggs. Journal of Fish Biology 66(6):1681-1691. DOI: 10.1111/j.0022-1112.2005.00715.x.

Jensen, D. W., E. A. Steel, A. H. Fullerton, and G. R. Pess. 2009. Impact of fine sediment on egg-to-fry survival of Pacific salmon: A meta-analysis of published studies. Reviews in Fisheries Science 17(3):348-359. DOI: $10.1080 / 10641260902716954$.

Johnson, F. H. 1961. Walleye egg survival during incubation on several types of bottom in Lake Winnibigoshish, Minnesota, and connecting waters. Transactions of the American Fisheries Society 90(3):312-322. DOI:10.1577/1548-8659(1961)90[312:WESDIO]2.0.CO;2

Kranck, K. 1980. Experiments on the significance of flocculation in the settling of fine-grained sediment in still water. Canadian Journal of Earth Sciences 17:1517-1526.

Lutz, C. H., D. G. Clarke, B. C. Suedel. 2012. A fish larvae and egg exposure system (FLEES) for evaluating the effects of suspended sediments on aquatic life. DOER Technical Notes Collection ERDC TN-DOER-E32. Vicksburg, MS: U. S. Army Engineer Research and Development Center. http://el.erdc.usace.army.mil/.

Reine, K. J., D. D. Dickerson, and D. G. Clarke. 1998. Environmental windows associated with dredging operations. DOER Technical Notes Collection. ERDC TN DOER-E2. Vicksburg, MS: U. S. Army Engineer Research and Development Center. http://el.erdc.usace.army.mil/.

Reiser, D. W., and R. G. White. 1988. Effects of two sediment size-classes on survival of steelhead and chinook salmon eggs. North American Journal of Fisheries Management 8:432-437.

Scott, W. W., and A. H. O’Bier. 1962. Aquatic fungi associated with diseased fish and fish eggs. The Progressive Fish-Culturist 24:3-15. DOI:10.1577/1548-8659(1962)24[3:AFAWDF]2.0.CO;2. 
Silver, S. J., C. E. Warren, and P. Doudoroff. 1963. Dissolved oxygen requirements of developing steelhead trout and chinook salmon embryos at different water velocities. Transactions of the American Fisheries Society 92(4):327-343. DOI: 10.1577/1548-8659(1963)92[327:DORODS]2.0.CO;2.

Steinhart, G. B., N. J. Leonard, R. A. Stein, and E. A. Marschall. 2005. Effects of storms, angling, and nest predation during angling on smallmouth bass (Micropterus dolomieu) nest success. Canadian Journal of Fisheries and Aquatic Sciences 62(11):2649-2660.

Suedel, B. C., J. Kim, D. G. Clarke and I. Linkov. 2008. A risk-informed decision framework for setting environmental windows for dredging projects. Science of the Total Environment. 403(1-3):1-11. DOI: 10.1016/j.scitotenv.2008.04.055.

Sutherland, B. R., K. J. Barrett, and M. K. Gingras. 2014. Clay settling in fresh and salt water. Environmental Fluid Mechanics 15(1):147-160. DOI: 10.1007/s10652-014-9365-0.

Ventling-Schwank, A. R., and D. M. Livingstone. 1994. Transport and burial as a cause of whitefish (Coregonus sp.) egg mortality in a eutrophic lake. Canadian Journal of Fisheries and Aquatic Sciences 51:1908-1919.

Wechsler, B. A., and D. R. Cogley. 1977. A laboratory study of the turbidity generation potential of sediments to be dredged. Technical Report U. S. Army Engineer Waterways Experiment Station D-77-14. Vicksburg, MS: U. S. Army Engineer Research and Development Center. Accession number: ADA055646. http://www.dtic.mil/dtic/.

Zumwalt, D. C., F. J. Dwyer, I. E. Greer and C. G. Ingersoll. 1994. A water-renewal system that accurately delivers small volumes of water to exposure chambers. Environmental Toxicology and Chemistry 13(8):1311-1314. DOI: $10.1002 /$ etc.5620130813.

NOTE: The contents of this technical note are not to be used for advertising, publication, or promotional purposes. Citation of trade names does not constitute an official endorsement or approval of the use of such products. 